\title{
ПСИХОЛОГІЧНІ ПРИНЦИПИ КОМУНІКАЦЙ ПРИ СТВОРЕННІ УПРАВЛІНСЬКИХ КОМАНД
}

\author{
Черкаський Андрій \\ Одеська національна академія харчових технологій \\ м. Одеса, Україна \\ e-mail: academy_@ukr.net \\ ORCID: 0000-0001-6227-3029
}

\begin{abstract}
Mema статті - розглянути та проаналізувати основні принципи й теоретичні моделі комунікацій в управлінських командах.

Memoдu. В основу дослідження покладено теоретичні методи: аналіз й узагальнення наукових джерел із проблем вивчення комунікації в управлінських командах.
\end{abstract}

Результати. У статті наведено основні визначення поняття «комунікація» в сучасній науці, проаналізовано процеси комунікації, що забезпечують ефективну роботу команди. Зазначено, що міжособистісне спілкування, обмін інформацією, тобто комунікація між членами команди, виступає основою для безпосереднього об'єднання людей в інтересах отримання синергетичного ефекту від спільної діяльності. Особливий акцент на тому, що здатність людей спілкуватися один з одним, тобто встановлювати канали комунікації, не $є$ єдиною умовою створення команд. Для команд важливим є формування ними комплексу власних норм і правил спільної роботи, рольова структура виконання обов'язків, особлива організаційна культура і стиль управління і т.д., однак всі вони можуть бути вироблені командою тільки за наявності добре сформованої системи комунікації між іiі учасниками. Отже, в командах вибудовується більш потужна мережа комунікаційних каналів, як за розгалуженістю, так і за обсягом інформації, що по них проходить.

У сучасних умовах здатність команд до створення системи комунікації одна 3 ключових їхніх компетенцій, а найважливішою умовою формування комунікаційного потенціалу команди $\epsilon$ довіра ï учасників один до одного. Створення атмосфери довіри в команді $є$ важливою складовою побудови i розвитку комунікаційної мережі, формування комунікаційної дифузії, відсутність яких фактично стане непереборною перешкодою для створення командами свого загального людського потенціалу, перетворення персоніфікованих знань в командні знання.

У висновках зазначено, що командна комунікація дозволяє не тільки забезпечити кращу реалізацію знань, умінь i навичок кожного учасника команди на своєму робочому місці, але і сформувати механізм, що забезпечує

ISSN 2308-3743 (Online), ISSN 2227-1376 (Print)

(C) Черкаський А., 2021. Ця стаття відкритого доступу на умовах CC BY-NC 4.0 
потоки ідей, знань і спостережень від одного члена команди до всіх його колег. Звернено увагу на те, що важливе значення має підготовка керівників команд, всього управлінського персоналу, навчання методів налагодження комунікаційних каналів, як по горизонталі, так і по вертикалі.

Ключові слова: комунікація, канали комунікації, міжособистісне спілкування, взаємодія, кооперація, інтеграція, синергетичний ефект, командна діяльність.

\section{Cherkassky Andrey. Psychological principles of communication in creating management teams.}

Purpose. The purpose of the article is to consider and analyze the basic principles and theoretical models of communication in management teams.

Methods. The research is based on theoretical methods: analysis and generalization of scientific sources on the problems of studying communication in management teams.

Results. The article presents the main definitions of the concept of "communication" in modern science, analyzes the communication processes that ensure effective team work. It is noted that interpersonal communication, information exchange, that is, communication between team members, acts as the basis for direct association of people in the interests of obtaining a synergistic effect from joint activities. Special emphasis is placed on the fact that the ability of people to communicate with each other, that is, to establish communication channels, is not the only condition for creating teams. For teams, it is important for them to form a set of their own norms and rules of joint work, the role structure of performing duties, a special organizational culture and management style, etc.However, all of them can be developed by a team only if there is a well-formed communication system between its participants. Thus, teams build a more powerful network of communication channels, both in terms of branching and the amount of information that passes through them.

In modern conditions, the ability of teams to create a communication system is one of their key competencies, and the most important condition for forming the communication potential of a team is the trust of its participants in each other. Creating an atmosphere of trust in the team is an important component of building and developing a communication network, the formation of communication diffusion, the absence of which will actually become an insurmountable obstacle to the creation of teams ' common human potential, the transformation of personalized knowledge into Team knowledge.

The conclusions indicate that team communication allows not only to ensure the best implementation of the knowledge, skills and abilities of each team member in their workplace, but also to form a mechanism that provides flows of ideas, knowledge and observations that one team member has to all their colleagues. It is emphasized that it is important to train team leaders, all management personnel, and train methods for establishing communication channels, both horizontally and vertically. 
Keywords: communication, communication channels, interpersonal communication, interaction, cooperation, integration, synergistic effect, team activity.

\section{Черкасский Андрей. Психологические принципы коммуникаций при создании управленческих команд.}

Цель статьи - рассмотреть и проанализировать основные принципы и теоретические модели коммуникаций в управленческих командах.

В основу исследования положены теоретические методы: анализ и обобщение научных источников по проблемам изучения коммуникации в управленческих командах.

Pезультаты. В статье приведены основные определения понятия «коммуникация» в современной науке, анализируются процессы коммуникации, обеспечивающие эффективную работу команды. Указано, что межличностное общение, обмен информацией, то есть коммуникация между членами команды, выступает основой для непосредственного объединения людей в интересах получения синергетического эффекта от совместной деятельности. Особый акцент делается на том, что способность людей общаться друг с другом, то есть устанавливать каналы коммуникации, не является единственным условием создания команд. Для команд важным является формирование ими комплекса собственных норм и правил совместной работы, ролевая структура исполнения обязанностей, особая организационная культура и стиль управления и т.д. однако все они могут быть произведены командой только при наличии хорошо сформированной системы коммуникации между еe участниками. Таким образом, в командах выстраивается более мощная сеть коммуникационных каналов, как по разветвленности, так и по объему проходящей по ним информации.

В современных условиях способность команд к созданию системы коммуникации является одной из их ключевых компетенций, а важнейшим условием формирования коммуникационного потенциала команды является доверие его участников друг к другу. Создание атмосферы доверия в команде является важной составляющей построения и развития коммуникационной сети, формирования коммуникационной диффузии, отсутствие которых фактически станет непреодолимым препятствием для создания командами своего общего человеческого потенциала, превращения персонифицированных знаний в командные знания.

В выводах указано, что командная коммуникация позволяет не только обеспечить лучшую реализацию знаний, умений и навыков каждого участника команды на своем рабочем месте, но и сформировать механизм, обеспечивающий потоки идей, знаний и наблюдений от одного члена команды ко всем его коллегам. Подчеркивается, что важное значение имеет подготовка руководителей команд, всего управленческого персонала, обучения методам налаживания коммуникационных каналов, как по горизонтали, так и по вертикали. 
Ключевые слова : коммуникация, каналы коммуникации, межличностное общение, взаимодействие, кооперация, интеграция, синергетический эффект, командная деятельность.

Вступ. Основним фактором, що визначає, чи $є$ група співробітників командою, виступає фактор взаємодії. Інакше кажучи, система відносин між людьми, що дозволяє їм діяти у своїй сукупності краще, ніж поодинці. Це і $є$ той фундамент, на якому будується вся конструкція команди. Цей факт дозволяє звернутися до дослідження команд 3 точки зору теорії комунікації, оскільки комунікації - ключовий фактор формування командної роботи.

Існує безліч визначень соціальної комунікації. Найбільш часто трапляються такі: соціальна комунікація - це передача інформації, ідей, емоцій за допомогою знаків, символів; це процес, який пов'язує окремі частини соціальних систем один 3 одним; це механізм, за допомогою якого реалізується влада (влада як спроба визначити поведінку іншої людини) (Бодди, Пейтон, 1999: 267).

Мета цієї статті - розглянути та проаналізувати основні принципи й теоретичні моделі комунікацій в управлінських командах.

Методи та процедура дослідження. В основу дослідження покладено теоретичні методи: аналіз та узагальнення наукових джерел із проблем вивчення комунікації в управлінських командах.

Обговорення результатів. Існують різні теоретичні моделі соціальної комунікації. В рамках психоаналітичної моделі, заснованої на теоретичних навчаннях 3. Фрейда i К. Юнга, комунікацію розуміють як витіснення індивідом своїх несвідомих потягів (Вацлавик и др., 2000).

Екзистенціалістська модель розглядає комунікацію як «закинутість у світ». Таке розуміння комунікації пояснюється розвитком у ХХ ст. системи моралі-індивідуалізму (Вацлавик и др., 2000).

У контексті біхевіоризму (науки про поведінку) основою комунікації є не мова як система, а безпосередні мовні сигнали, маніпулюючи ними, можна виховувати людину будь-якого складу. Таке ж розуміння комунікації ми бачимо і в семантичній моделі Ю. Лотмана (Лотман, 1998) і У. Эко. 
В ігровій моделі комунікації, основними представниками якої можна назвати Е. Берна і Й. Хейзінга, комунікація є гра. Персоналізм розглядає комунікацію як внутрішню метафізичну здатність особистості відкривати в собі почуття іншого (відносини Я-інший) (Эльконин, 1978; Хейзинга, 1997). У розуміючій моделі комунікації, основними представниками якої є М. Вебер, Г.-Г. Гадамер, Г. Шпет, головним результатом комунікації $\epsilon$ розуміння людиною іншої людини, так зване взаємне розуміння (Гадамер, 1988; Шпет, 2007).

Широке визнання й поширення набула лінійна модель комунікації, розроблена відомим американським соціологом i політологом Г. Ласуелом, що включає п’ять елементів (Lasswell, 1948). На сьогодні існує багато сучасних досліджень, присвячених реляційним аспектам комунікації (Trenholm, Jensen, 2013), аудіовізуальному сприйняттю повідомлень (Barkhuysen, Krahmer, 2004), теорії прихильності Джона Боулбі і Мері Ейнсворт (Bretherton, 1992) та ін.

Різні аспекти соціальної комунікації розглядали також вітчизняні дослідники. Серед них: проблеми розвитку організаційних комунікацій в Україні (Колісниченко, 2014), глобальні проблеми сучасного інформаційного суспільства (Зернецька, 2017; Горова, 2017), загальні принципи комунікації (Бобало, 2015; Бутиріна, 2018), проблеми інформаційної культури ( Прудникова, 2015) та ін.

У сучасних умовах система комунікацій виступає ключовим чинником об'єднання людей у команди, найважливішою складовою яких $є$ взаємодія і широка мережа взаємозв'язків, кооперація та інтеграція між членами команд, відкритість команд як до вимог зовнішнього середовища, так i до будь-яких ідей i новацій, що народжуються всередині таких формувань.

Аналіз діяльності команд показує, що взаємодія, тобто комплекс процесів комунікації, $є$ основою, що забезпечує ефективну роботу команди. Проведені автором дослідження серед працівників виробничих підприємств півдня України показують, що здатність до комунікації - важлива компетентність для всіх учасників команд. Опитування проводилось в Одеській та Миколаївській областях. Вибірка склала 200 осіб - співробітники різних відділів виробничих підприємств. Так, на питання, «Якби ви працювали командою, які якості колег, що працюють поруч, були б для Вас важливими, оскільки від них залежить досягнення успіху», відповіді 
розподілилися таким чином: більше $80 \%$ опитаних відповіли, що такою якістю є професіоналізм, 78\% - відповідальність, 70\% - вміння співпрацювати з колегами, відповідно 45\% і 40\% - надійність і висока працездатність.

Як бачимо, вміння співпрацювати, тобто обговорювати завдання, узгоджувати між собою робочі процеси, виробляти норми $і$ правила спільної діяльності високо цінується в командах. Міжособистісне спілкування, обмін інформацією, спостереженнями, ідеями, поглядами, тобто комунікація між членами команди виступає в цьому випадку основою для безпосереднього об'єднання людей в інтересах отримання синергетичного ефекту від спільної діяльності. Інакше кажучи, сам факт наявності комунікації вже засвідчує, що група людей має у своєму розпорядженні певний комунікаційний потенціал, який може стати основою для перетворення цієї групи в команду.

У зв'язку 3 цим слід зауважити, що здатність людей спілкуватися один з одним, тобто встановлювати канали комунікації, не $\epsilon$ єдиною умовою створення команд. Для команд важливим $\epsilon$ формування ними комплексу власних норм і правил спільної роботи, рольова структура виконання обов'язків, особлива організаційна культура та стиль управління і т.д., однак всі вони можуть бути вироблені командою тільки за наявності добре сформованої системи комунікації між іiі учасниками. Отже, в командах вибудовується більш потужна мережа комунікаційних каналів, як за розгалуженістю, так і за обсягом інформації, що по них проходить.

На важливість і необхідність розвитку комунікацій вказують i зарубіжні дослідники. Так, автори основ менеджменту М. Мескон, М. Альберт і Ф. Хедоурі відзначають, що «75\% американських, 63\% англійських і 85\% японських керівників вважають погані комунікації головною перешкодою на шляху досягнення ефективності їхніми організаціями» (Мескон, Альберт, Хедоури, 1995).

Отже, вирішуючи завдання побудови командної діяльності, важливо знати, що поряд із якостями, що характеризують людину 3 професійного боку, необхідні якості, що розкривають його здатності до комунікації і взаємодії. Існує кілька підходів, дотримання яких може забезпечувати комунікацію між учасниками команд. Їх можна класифікувати як принципи командної комунікації, на базі яких 
люди забезпечують кооперацію всередині команди. До основних принципів належать такі:

принцип комунікаційної дифузї, що забезпечує процес взаємного вибудовування каналів комунікації між усіма учасниками команди, що призводить до мимовільного вирівнювання концентрацій прямих і зворотних зв'язків, включення в них усіх учасників команди;

- принцип, близький до вищевказаного - паралельних двосторонніх комунікаційних потоків. Цей принцип забезпечує зворотний зв'язок для відправника інформації. Дотримання його допомагає команді оперативно приймати рішення, виявляти недоліки або проблеми, швидко реагувати на творчі, креативні пропозиції;

принцип відкритості комунікації, який забезпечує доступність каналів комунікації між керівником команди та іiі рядовими учасниками, між новачками і «старожилами», молодими i людьми старшого віку. Важливість цього принципу особливо важлива на етапі формування команди, налагодження та формування каналів комунікації.

Спостереження над кращими командами показує, що вони активно використовують такі комунікаційні канали, як бенчмаркінг пошук передового досвіду, доведення його до кожного учасника команди та спільне його використання (Дубовик, 2005; Меренюк, 2007; Прищепа, 2005); мозкові атаки як метод комунікаційної активізації творчої ініціативи учасників команд при розробці креативних ідей (Джанкинс, 2016); ретріти - навчання учасників команди в рамках регулярних обмінів думками, що дозволяє вивільнити інноваційний потенціал членів команд, залучити їх до пошуку нових ідей щодо організації спільної роботи.

Отже, можна зробити висновок, що джерелом ключових здібностей команд $€$ наявність потужної системи комунікації всередині команди, що забезпечує створення, передачу, інтеграцію та експлуатацію знань як активів. Однак слід підкреслити, що незважаючи на свою важливу роль у діяльності команди, система іiі комунікації так само залежить від ряду важливих психологічних характеристик, властивих командам. Дослідження, проведені автором, показують, що ключовою 3 них $є$ прихильність учасників команд до цінності довіри один до одного. Саме довіра до колег стає тим інструментом, який локалізовані знання, тобто ті, що належать 
одній людині, перетворює на де-локалізовані, що належать усім (Ильин, 2013). На високу роль довіри в економіці як фактора, що забезпечує комунікацію, вказують і інші автори (Соболева, 2008: 379).

Отже, команди з високим рівнем довіри ще швидше вчаться на своєму і чужому досвіді. При цьому довіру розглядають у зв'язку 3 різними аспектами життєдіяльності груп; це ефективність діяльності (Роббинз, 2006), згуртованість, поведінка членів групи (Нестик, 2005), статусні відносини в групі (Aubert, Kelsey, 2003), адаптація новачків у групі, розвиток групи (Bain, 2001; West, 1990).

Висновки. Отже, комунікація в команді, за своєю суттю, забезпечує набуття додаткових переваг з індивідуальних професійних якостей iї учасників. Інакше кажучи, командна комунікація дозволяє не тільки забезпечити кращу реалізацію знань, умінь i навичок кожного учасника команди на своєму робочому місці, але i сформувати механізм, що забезпечує потоки ідей, знань і спостережень від одного члена команди до всіх його коллег, і на цій основі домогтися не тільки кращої координації діяльності всіх членів команди, але й забезпечити ефективність іiі функціонування як в оперативному плані, так і в довгостроковій перспективі.

Перспективи подальших досліджень ми вбачаємо у проведенні емпіричного дослідження та розробки тренінгової програми щодо поліпшення комунікації в управлінських командах.

\section{Література}

1. Бодди, Д. Пейтон, Р. (1999). Основы менеджмента. СПб.

2. Бутиріна, М. В. (2018). Наукові дослідження соціальних комунікацій в Україні. Вісник Харківського начіонального університету імені В. Н. Каразіна. Серія: «Сочіальні комунікаиїі»,11, 119-121.

3. Вацлавик, П., Бивин, Дж., Джексон, Д. (2000). Прагматика человеческих коммуникаций: Изучение паттернов, патологий и парадоксов взаимодействия. Москва: Апрель-пресс.

4. Гадамер, Х.-Г. (1988). Истина и метод: Основы философской герменевтики. Москва: Прогресс.

5. Горова, С. В. (2017). Особа в інформаційному суспільстві: виклики сьогодення. Київ, НАН України, Нац. б-каУкраїни імені В. І. Вернадського.

6. Джанкинс, Р. ( 2016). Искусство креативного мышления. Москва: Азбука-Аттикус.

7. Дубовик, О. (2005). Формування конкурентних переваг на основі бенчмаркингу. Регіональна економіка, 3, 134-137. 
8. Зернецька, О. В.(2017). Глобальна комунікація. Київ, Наукова думка.

9. Ильин, Е. П. (2013). Психология доверия. СПб.: Питер.

10. Колісниченко, Т. В., Мироненко, В. В. (2014). Організаційні комунікаиії (реклама та паблік рилейшнз) як поліпарадигмальний феномен. Дніпропетровськ.

11. Лотман, Ю. М. (1998). Структура художественного текста. Об искусстве. СПб.: «Искусство - СПБ».

12. Меренюк, Т. В. (2007). Бенчмаркінг - шлях до конкурентних переваг. Наука та практика. Полтава, 152-153.

13. Мескон, М. Х., $\quad$ Альберт, М., $\quad$ Хедоури, Ф. (1995). Основы менеджмента. Москва.

14. Нестик, Т. А. (2005). Доверие в команде: преимущества, риски, методы, проблемы развития. Справочник по управлению персоналом, 6.

15. Прищепа, В. А. (2005). Применение метода бенчмаркинга для совершенствования систем менеджмента качества испытательных центров и лабораторий. Актуальні проблеми економіки, 3(45), 110-116.

16. Прудникова, О.В. (2015). Інформаційна культура: концептуальні засади та світоглядний сенс. Харків: Право.

17. Роббинз, С. П. (2006). Основы организаиионного поведения. Москва.

18. Хейзинга, Й.(1997). Hoто Ludens; Статья по истории культурыл. Москва.

19. Соболева, И. В. (2008). Деформация социального капитала и перспективы их преодоления. Неэкономические грани экономики: неопознанное взаимовлияние. Москва.

20. Шпет, Г. Г. (2007). Искусство как вид знания. Избранные труды по философии культуры. Москва: РОССПЭН.

21. Эльконин, Д. Б. (1978). Психология игры. Москва.

22. Aubert, B. A., Kelsey, B. L. (2003). Further understanding of trust and performance in virtual teams. Small Group Research, 34 (5), 575-618.

23. Bain, P. L., Mann, L., Pirola-Merlo, A. (2001). The Innovation Imperative: The Relationships Between Team Climate, Innovation, and Performance in Research and Development Teams. Small Group Research, 32(1), 55-73.

24. Barkhuysen, P., Krahmer, E., Swerts, M. (2004). Audiovisual Perception of Communication Problems, ISCA Archive http://www.isca-speech.org/archive

25. Bretherton, I., (1992) The Origins of Attachment Theory: John Bowlby and Mary Ainsworth. Developmental Psychology, 28, 759-775.

26. Lasswell. (1948). The structure and function of communication in society. The Communication of Ideas. N.Y.: Harper and Brothers.

27. Trenholm, S., Jensen, A. (2013). Interpersonal Communication Seventh Edition, 360-361. New York: Oxford University Press.

28. West, M. A. (1990). The social psychology of innovation in groups. Innovation and creativity at work: Psychological and organizational strategies I M. A. West, J. L. Farr (eds.), 309-333. Chichester, UK: Wiley. 


\section{References}

1. Boddi, D. Peyton, R. (1999). Osnovy menedzhmenta [Fundamentals of management]. $\mathrm{SPb}$ [in Russian].

2. Butyrina, M. V. (2018). Naukovi doslidzhennia sotsialnykh komunikatsii v Ukraini[Scientific research of Social Communications in Ukraine]. Visnyk Kharkivskoho natsionalnoho universytetu imeni V. N. Karazina. Seriia: «Sotsialni komunikatsii» - Bulletin of V. N. Karazin Kharkiv National University. Series: "Social Communications», 11, 119-121 [in Ukrainian].

3. Vaclavik, P., Bivin, Dzh., Dzhekson, D. (2000). Pragmatika chelovecheskih kommunikacij: Izuchenie patternov, patologij $i$ paradoksov vzaimodejstvija [Pragmatics of human communications: The study of patterns, pathologies and paradoxes of interaction]. Moskva: Aprel'-press [in Russian].

4. Gadamer, H.-G. (1988). Istina $i$ metod: Osnovy filosofskoj germenevtiki [Truth and method: Fundamentals of Philosophical hermeneutics]. Moskva: Progress [in Russian].

5. Horova, S. V. (2017). Osoba $v$ informatsiinomu suspilstvi: vyklyky sohodennia[personality in the information society: challenges of our time]. Kyiv, NAN Ukrainy, Nats. b-ka Ukrainy im. V. I. Vernadskoho [in Ukrainian].

6. Dzhankins, R. ( 2016). Iskusstvo kreativnogo myshlenija [The art of creative thinking]. Moskva: Azbuka-Attikus. [in Russian].

7. Dubovik, O. (2005). Formuvannja konkurentnih perevag na osnovi benchmarkingu [Formation of competitive advantages based on benchmarking]. Regional'na ekonomika, 3, 134-137 [in Ukrainian].

8. Zernetska, O. V.(2017). Hlobalna komunikatsiia: monohrafiia[Global communication: a monograph]. Kyiv, Naukova dumka [in Ukrainian].

9. Il'in, E. P. (2013). Psihologija doverija [Psychology of trust]. SPb.: Piter [in Russian].

10. Kolisnychenko, T. V., Myronenko, V. V. (2014). Orhanizatsiini komunikatsii (reklama ta pablik ryleishnz) yak poliparadyhmalnyi fenomen [Organizational communications (advertising and public relations) as a polyparadigmal phenomenon]. Dnipropetrovsk [in Ukrainian].

11. Lotman, Ju. M. (1998). Struktura hudozhestvennogo teksta. Ob iskusstve [The structure of a literary text. About Art]. SPb.: «Iskusstvo - SPB» [in Russian].

12. Merenjuk, T. V. (2007). Benchmarking - shljah do konkurentnih perevag [Benchmarking is the path to competitive advantages]. Nauka ta praktika - Science and practice. Poltava, 152-153 [in Ukrainian].

13. Meskon, M. H., Al'bert, M., Hedouri, F. (1995). Osnovy menedzhmenta[ Fundamentals of management]. Moskva [in Russian].

14. Nestik, T. A. (2005). Doverie v komande: preimushhestva, riski, metody, problemy razvitija [Trust in the team: advantages, risks, methods, development problems]. Spravochnik po upravleniju personalom - Handbook of Personnel Management, 6 [in Russian].

15. Prishhepa, V. A. (2005). Primenenie metoda benchmarkinga dlja sovershenstvovanija sistem menedzhmenta kachestva ispytatel'nyh centrov i 
laboratorij [Application of the benchmarking method for improving the quality management systems of testing centers and laboratories]. Aktual'ni problemi ekonomiki - Current problems of economics, 3(45), 110-116 [in Russian].

16. Prudnykova, O. V. (2015). Informatsiina kultura: kontseptualni zasady ta svitohliadnyi sens[Information culture: conceptual foundations and ideological meaning]. Kharkiv: Pravo [in Ukrainian].

17. Robbinz, S. P. (2006). Osnovy organizacionnogo povedenija [Fundamentals of organizational behavior]. Moskva [in Russian].

18. Hejzinga, J. (1997). Homo Ludens; Stat'ja po istorii kul'tury [Homo Ludens; Article on cultural history]. Moskva [in Russian].

19. Soboleva, I. V. (2008). Deformacija social'nogo kapitala i perspektivy ih preodolenija [The deformation of social capital and the prospects for overcoming them]. Nejekonomicheskie grani jekonomiki: neopoznannoe vzaimovlijanie - Noneconomic facets of the economy: unidentified mutual influence. Moskva [in Russian].

20. Shpet, G. G. (2007). Iskusstvo kak vid znanija [Art as a kind of knowledge]. Izbrannye trudy po filosofii kul'tury - Selected works on the philosophy of culture. Moskva: ROSSPJeN [in Russian].

21. Jel'konin, D. B. (1978). Psihologija igry [Game Psychology]. Moskva [in Russian].

22. Aubert, V. A., Kelsey, B. L. (2003). Further understanding of trust and performance in virtual teams. Small Group Research, 34(5), 575-618.

23. Bain, P. L., Mann, L., Pirola-Merlo, A. (2001). The Innovation Imperative: The Relationships Between Team Climate, Innovation, and Performance in Research and Development Teams. Small Group Research, 32(1), 55-73.

24. Barkhuysen, P., Krahmer, E., Swerts, M., (2004) Audiovisual Perception of Communication Problems, ISCA Archive http://www.isca-speech.org/archive

25. Bretherton, I. (1992) The Origins of Attachment Theory: John Bowlby and Mary Ainsworth, Developmental Psychology, 28, 759-775.

26. Lasswell. (1948). The structure and function of communication in society. The Communication of Ideas. N.Y.: Harper and Brothers.

27. Trenholm, S., Jensen, A. (2013). Interpersonal Communication Seventh Edition. New York: Oxford University Press, 360-361.

28. West, M. A. (1990). The social psychology of innovation in groups. Innovation and creativity at work: Psychological and organizational strategies I M. A. West, J. L. Farr (eds.), (pp. 309-333). Chichester, UK: Wiley.

Received: 06.05.2021

Accepted: 22.05.2021 